\section{Subempleo y desempleo, un lugar para el trabajo de las mujeres}

\author{
Isabel Gamboa Barboza*
}

\section{RESUMEN}

Las experiencias laborales de las mujeres y los hombres se fundamentan, en mucho, sobre disposiciones de género. Dentro del mercado laboral -por medio de los salarios, los puestos, los ascensos y los oficios-se actúan las ideas que tenemos de cómo son las mujeres y de cómo son los hombres. De esta forma, las mujeres entran al mercado laboral desde un lugar de modestas, sin ambiciones, altruistas y con la maternidad como centro de su vida, por lo que el hecho de que se les pague menores salarios, se les exija más, se les ascienda menos y se las excluya de los puestos de mayor poder, pasa a ser un detalle natural. Este trabajo habla de eso y de cómo, en un contexto de "flexibilización" laboral, las mujeres son más apetecidas por un mercado que cada vez quiere más a cambio de menos.

\footnotetext{
Licenciada en Sociología. Tiene varias publicaciones sobre esta temática y actualmente es funcionaria del Programa Atención Integral de Salud UCR-CCSS. Correo: ilione@racsa.co.cr Rec. 7-3-05/Acep. 28-9-05
}

También discute de cómo ese mismo mercado, al tiempo que refuerza estereotipos de género, contribuye a su descentramiento.

\section{PALABRAS CLAVE}

Experiencias laborales, Disposiciones de género, Mercado laboral, Subempleo y desempleo, Trabajo de mujeres, Flexibilización laboral, y Estereotipos de género.

\section{ABSTRACT}

Women and men working experiences are generally based on gender dispositions. By means of wages, positions, promotions and occupations we can have an idea on how women and men are within the labor market. Women enter the labor market from a level of modesty and altruism, with no ambitions and with maternity as their lives axis. Therefore, the fact that women are underpaid, over demanded, not promoted as frequently, and generally excluded of more authoritative positions becomes a natural detail. This article is based on that and on how within the context of labor "flexibilization" women are demanded more frequently by a market that wants more in return for less. It also discusses how that same market contributes to the abolition of gender decentralization while reinforcing gender stereotyping.

\section{KEY WORDS}

Labor experiences, Gender Dispositions, Labor Market, Underemployment and Unemployment, Women Work, Labor Flexibilization, Gender Stereotypes. 
"Tal vez es en la esfera del trabajo donde el patriarcado presenta una mayor flexibilidad de ajuste a las nuevas condiciones estructurales, mostrando formas de readecuación casi automáticas, flexibilidad que ha hecho posible hablar de una "ajuste estructural permanente" del patriarcado en dicha esfera."

Adriana Muñoz D`Albora

Tal parece que las mujeres nos movemos entre el desempleo, el subempleo y los trabajos con las peores condiciones, con mayor continuidad que los hombres. Esto tiene que ver con que las condiciones del mercado laboral están, de seguro, atravesadas por las disposiciones de género.

Uno de los mensajes, que tanto tácita como explícitamente, recibimos las mujeres desde la niñez, es el de que nuestra "máxima realización" está en el matrimonio y la maternidad, y debido a la carga sexista de ese mandato, ambas cosas entran en fuerte contradicción con la vivencia de un trabajo asalariado. Solo por referir una consecuencia, si se considera la casa -lugar del matrimonio y la maternidad- como el espacio "natural" de las mujeres, esa valoración influye, de manera negativa, en las oportunidades, salarios y calificaciones del trabajo realizado fuera de ese lugar "original", casi podríamos decir que laboralmen- te las mujeres terminamos siendo una especie de extranjeras, sobre todo si se incursiona en profesiones o especialidades "masculinas". Como dice León, existe una brecha estructural e histórica que expulsa a las mujeres de la competencia, pues entran en el mercado laboral ya perdiendo (León, 2002).

Se sobreentiende que lo hecho por las mujeres, para la reproducción de la familia, es trabajo, pero que ello nunca ha implicado una retribución económica ni que se le nombre como tal. El pensar siquiera que lo que una mujer realiza, en su papel de madre-esposa, tiene un costo económico, es algo que va contra la moral altruista que el patriarcado ha enseñado a las mujeres, es indecente. A veces parece que la demanda de filantropía a las mujeres llega a extremos irónicos, cuando, participando en trabajos formalmente reconocidos como tales, es como si se insistiera tácitamente en nuestra abnegación, para mal pagarnos.

Pero en contradicción con los mandatos de ser y estar en la casa, la realidad es que las mujeres "estamos afuera". Las mujeres dentro de la casa es solo una fantasía de la cultura misógina, fantasía que se opone a la existencia de cada vez más mujeres que se incorporan al mercado laboral. 
Dicho aumento se advierte desde varias perspectivas: según un estudio del BID, citado por Duddy, el aumento en la participación de mujeres en trabajos remunerados, está relacionado con una disminución en la fertilidad, un aumento en la escolaridad y en la demanda de mano de obra femenina (Duddy, 2003); por su parte, Flórez- Estrada opina que ese aumento se explica por la reivindicación que las mujeres han hecho del derecho a ingresar a dicho espacio, porque las mujeres son un ejército de reserva del cual está echando mano el capital, y porque esta incorporación de las mujeres permite al

Estado alejarse de sus obligaciones sociales, y ofrece la ventaja, al capital, de empequeñecer el costo de la fuerza de trabajo en general (Flórez-Estrada, 2003).

\section{Costos}

\section{de la feminidad}

Sea por una decisión independiente y personal, empujada por la necesidad económica, atraídas por el mercado, o cualquier otra circunstancia, cuando una mujer ingresa al mercado de trabajo, lo hace en condiciones marcadas por su género, ya que los supuestos que se actúan sobre el papel de las mujeres, básicamente reproductivo y no productivo, se representan en los tipos de empleo que se consideran femeninos o masculinos (Duddy, 2003). Esto es, el mercado laboral ofrece a las mujeres empleos demasiado parecidos a las ocupaciones reproductivas, y espera pagarles por éstos precios inferiores a los pagados a los hombres. Por ejemplo, un estudio revela que en la industria, en 27 de los 39 países con datos disponibles, las mujeres ganaban entre 20 a 50 por ciento menos que los hombres (Fontenele, 2003).

Dicho directamente, prevalece la práctica de pagar menos a las mujeres solo por el hecho de serlo, independientemente de las circunstancias que se puedan considerar. Pero evidentemente, esas circunstancias a veces empeoran la condición laboral de las mujeres, por ejemplo, si además de ser mujer se tiene baja escolaridad.

Las mujeres con baja escolaridad, que trabajan asalariadamente, se enfrentan al absurdo de que su salario no alcanzará siquiera, para pagar por la realización del trabajo doméstico de su casa. Una mujer tiene que decidir qué hacer ante la realidad de que por serlo no tuvo oportunidades para estudiar, sin estudio tendrá que conformarse con un muy bajo salario, con bajo 
salario sus posibilidades de independizarse son ínfimas (FlórezEstrada, 2003).

Veamos un detalle más: si una mujer tiene que trabajar pero no está lo suficientemente calificada para conseguir el salario necesario, tendrá que bajar los costos de mantenimiento y una manera de hacerlo es consiguiendo gratis algunos servicios; nuevamente, como lo menos valorado, lo "regalable" por excelencia, es el trabajo doméstico, será esto lo que la mujer podrá conseguir gratuitamente a través de sus hijas o de su propia madre. Al respecto, una investigación para el caso de Costa Rica, realizada en el marco del proyecto PROMICRO, completa diciendo que las mujeres pobres pueden trabajar, en la mayoría de los casos, solo si sus hijas asumen las tareas reproductivas; esto implica, casi siempre, que desertarán de la educación formal, con lo cual estarán condenadas a trabajos mal pagados que limitan su posibilidad de pagar por el oficio doméstico, lo que las obligará a designar a sus propias hijas para ello ( PROMICRO-OIT, 2000). Para muchas generaciones de mujeres, es como si vivieran frente a un espejo que proyecta, una y otra vez, la misma imagen.

\section{La "clase" en el trabajo}

El tema del trabajo asalariado en las mujeres está atravesado por contradicciones y clasificaciones imaginarias que contribuyen a su baja estima.

A pesar del discurso, aún predominante, de que son los hombres los principales responsables de proveer económicamente a la familia, las crisis latinoamericanas han comenzado a mover dicho patrón. Al aumentar el desempleo, las mujeres, como responsables finales de la reproducción, se sienten compelidas para incorporarse a un mercado laboral, que por razones que veremos más adelante, prefiere mano de obra femenina (específicamente mujeres jóvenes y solteras) para ciertos oficios.

Ese aumento en la incorporación de las mujeres al mercado laboral, se da en empleos más inestables y peor remunerados (Merlinsky, 2001).

Lo anterior está relacionado, como mencionamos previamente, con la valoración del trabajo femenino desde una mirada de género, pero también tiene que ver con que el mercado laboral al que se insertan las mujeres, se caracteriza por el efecto que las políticas neoliberales tienen sobre las legislaciones de los países, políticas que les obligan 
a "flexibilizar" las condiciones de trabajo, o sea, a brindar una mano de obra más calificada y barata, que en la mayoría de los casos es femenina (León, 2002).

Debido a las nuevas formas de contratación laboral, producto de la "flexibilización", el mercado prefiere la mano de obra femenina, ya que las mujeres, por su baja escolaridad y por la obligatoriedad de trabajar para sustentar a sus familias, pueden ser contratadas con menores garantías sociales y con una mayor demanda de productividad.

$\mathrm{Y}$ es que de todos modos, el dinero que lleva a casa una mujer con pareja, no se toma muy en serio. Es común escuchar que una mujer que trabaja, teniendo marido $\mathrm{O}$ compañero, lo que hace es "ayudar"; su dinero se toma como un añadido al dinero principal, que se supone aportado por el hombre. Sin importar que las condiciones materiales de muchas familias desmienten dicha creencia, mercado y patriarcado se acuerpan mutuamente en la interiorización o minimización del trabajo de las mujeres.

Consideremos otro ejemplo. La fuerza de trabajo femenina es tradicionalmente tomada como una fuerza de trabajo secundaria.
D'Albora opina que no es secundaria, sino subordinada, ya que al estar la estructura ocupacional mediada por el género, éste deviene en una característica de las ocupaciones ya que "...los roles laborales y los tipos de trabajo están definidos por ideas estereotipadas sobre lo que son trabajos de mujeres y trabajos de hombres" (D'Albora, 1991:73). La globalización contribuye en el fortalecimiento de estereotipos de géneros.

La clasificación laboral se extiende hasta los estudios cuyo objetivo es mostrar o explicar la realidad del empleo. Según Prieto todos los estudios sobre el empleo clasifican en empleo, cesación, empleo temporal y empleo parcial, y jerarquizan, no solo a las situaciones de empleo, sino a las personas que les ocupan (Prieto, 2003). Agrega que esta jerarquización afecta sobre todo a las mujeres, al ser ellas las que principalmente ocupan los trabajos con peores condiciones, de modo que el valor con el que se juzga, por ejemplo, un empleo de tiempo parcial, pasa a ser el valor con el que se juzga a la mujer que lo desempeña. De ahí que devaluada la situación de empleo, devaluada la persona o mujer que lo ocupe. 


\section{Del medio empleo al desempleo}

$\mathrm{Al}$ ser las mujeres un grupo devaluado, se justifica y se entiende que ocupemos, como mayoría, las listas de subempleo (Prieto, 2003) y los puestos más desventajosos. Las relaciones de género ocasionan que la fuerza de trabajo femenina se concentre en actividades que muestran altos niveles de explotación, y una inclinación acelerada al desempleo (D`Albora, 1991).

De acuerdo con los dispositivos de género, el empleo de las mujeres se concentra en los sectores de servicios personales, sociales y comunales; gobierno; comercio e industria. Un estudio revela que las horas que las mujeres trabajan remuneradamente, han disminuido en comparación con las de los hombres, obviamente esta reducción en las horas laboradas ocasiona que sus salarios también mengüen (Montiel, citada por Flórez-Estrada, 2003). La disminución en las horas que las mujeres trabajan asalariadamente se relaciona con que las mujeres pueden trabajar solo tiempo parcial por las obligaciones domésticas.

En el mismo sentido, una investigación, aludida anteriormente, señala que la reducción en las jornadas laborales, de manera involuntaria, es decir por ausencia de trabajo, es la más trascendente forma de subempleo y afecta con mayor y progresiva intensidad a las mujeres (PROMICRO, 2000).

El mismo estudio añade que la tasa de desempleo entre las mujeres saltó, del $6 \%$ en 1990, al $8 \%$ en 1998, entre tanto, la de los hombres se mantuvo en $4 \%$ (PROMICRO, 2000). Se apunta que una característica que distingue al desempleo en las mujeres, es que éstas son más sensibles a las coyunturas recesivas, lo que se traduce en que el desempleo en las mujeres aumenta rápidamente, mientras que el de los hombres lo hace de manera más lenta o leve (PROMICRO, 2000).

También relacionado con el desempleo o subempleo, un estudio para el caso de Chile, reporta que las mujeres se retiran de la fuerza de trabajo mientras crían a los hijos y las hijas y reingresan a ésta una vez que terminan esa crianza (D`Albora, 1991). Sin duda existe una gran presión sobre las mujeres, aún sobre las profesionales, en el sentido de que su principal función o responsabilidad continúa siendo la crianza de las hijas y los hijos.

Agrega la investigación que “...la relación entre ciclos económicosfuerza de trabajo femenina es de naturaleza anticíclica; esta última tenderá a disminuir en aquellos ciclos expansivos En la crisis, la mujer y sobre todo la mujer de los 
sectores populares, entrará a presionar el mercado de trabajo como una de las múltiples estrategias que debe poner en práctica para enfrentar los problemas de supervivencia familiar. Dada la gravedad de la situación, la mujer buscará y se insertará en cualquier tipo de trabajo aunque sea mal remunerado y muestre las peores condiciones concretas de realización” (D`Albora, 1991:96).

Respecto a los efectos que el desempleo tiene en la identidad de las mujeres y de los hombres, Merlinsky asegura que a los hombres, debido a que el fundamento de su identidad es el ser proveedores, el desempleo les significa un descalabro o desajuste en su identidad de género (Merlinsky, 2001). Un hombre que no trabaja "no es un hombre". El trabajo puede significar para los hombres la posibilidad de "conseguir" y "mantener" mujeres, símbolo, en nuestra cultura machista, de virilidad.

Para las mujeres, cuya imagen ha sido construida más centrada en lo reproductivo, el desempleo implica un corte espacial (no viajar al trabajo) más no temporal, pues ellas reconstruyen su tiempo en el espacio doméstico del que de por sí nunca se desentendieron completamente (Merlinsky, 2001). Afirma la autora que incluso para aquellas mujeres que trabajan en los empleos más miserables, el desempleo significa un riesgo real de carencia absoluta, pero no una crisis de identidad; una excepción sería el caso de mujeres que, habiendo roto de alguna manera con los mandatos de género, centren su identidad en una carrera profesional (Merlinsky, 2001).

\section{CONCLUSIONES}

Al reflexionar sobre la presencia de las mujeres y de los hombres en el mercado laboral, resulta relativamente fácil darse cuenta de las diferencias que se dan en los puestos, pagos, ascensos, y garantías sociales que viven unas y otros. Lo que resulta difícil, es percatarse de que lo laboral es un escenario que muestra, y es producto, de relaciones precisas entre un sistema económico y otro patriarcal, o quizá mejor, es producto de un sistema patriarcalneoliberal. Puede parecer confuso advertir cómo el mercado lucra de la construcción cultural del sexo y cómo dicha construcción se ve reforzada por la lógica del mercado.

Pero la lucha por un mundo económicamente más justo, no puede desconocer que, además de los datos, en lo laboral tiene existencia lo simbólico, donde, finalmente, se actúa y reproduce el imaginario básico de que las mujeres son de la casa y los hombres de la calle. 


\section{BIBLIOGRAFÍA}

Duddy, Janice, 2003. Cómo está impactando la feminización de la fuerza laboral en América Latina a la salud de las mujeres. Texto difundido por revista la Tertulia: http:/www.la-tertulia.net

Flórez-Estrada Pimentel, María, 2003. Por una "feminización" de calidad. Semanario Universidad, Sección País. Pp. 4 y 5, n.o 1516, 7 de marzo.

Fontenele, Tânia, 2003. Globalización y su impacto en el universo femenino del trabajo. Texto difundido por la revista Tertulia: http:/www.la-tertulia.net

León, Irene, 2002. Cambios estructurales para la igualdad de género. Servicio Informativo de ALAI. Agencia Latinoamericana de Información. Quito. info@alai.ecuanex.net.ec
Merlinsky, María Gabriela, 2001. Desocupación y crisis en las imágenes de género. En: Mujeres en América Latina transformando la vida, Poggio, Sara; Sagot, Montserrat; Schmukler, Beatriz (comp.). San José. Pp. 101-131. Edición de la Maestría Regional en Estudios de la Mujer, Universidad de Costa Rica, Universidad Nacional.

Muñoz D`Albora, Adriana, 1991. Fuerza de trabajo femenina; evolución y tendencias. En: Género, Clase y Raza en América Latina. Algunas aportaciones. Luna, Lola (comp.). Barcelona. Pp. 63-130. Edición del Seminario Interdisciplinar Mujeres y Sociedad.

Prieto, Carlos, 2003. Los estudios sobre mujer, trabajo y empleo: caminos recorridos, caminos por recorrer. Texto difundido por revista la Tertulia: http:/www.la-tertulia.net

PROMICRO-OIT, INAMU PRONAMYPE, 2000. La mujer microempresaria en Costa Rica años 90. Cuadernos de trabajo n. ${ }^{\circ}$ 5. San José. 